\title{
NEW TYPE CAM-SCREW MECHANICAL PRESS
}

\author{
Erlan Askarov, Algazy Zhauyt, Zhastalap Abilkaiyr, Adilet Zhankeldi, Batyr Naurushev \\ Kazakh National Research Technical University named after K. I. Satpayev \\ erlan57@mail.ru, ali84jauit@mail.ru, jastalap81@mail.ru, adilet.zhankeldi@gmail.com, \\ batyr_n@mail.ru
}

\begin{abstract}
The article deals with the original design of a new type mechanical press - a cam-screw press. The proposed press has several advantages over the crank press: high efficiency, simple structure, reliable performance, high fixity. On the basis of the considered scheme there is proposed a new scheme of a sheetbending machine.
\end{abstract}

Keywords: mechanical press, crank press, cam-screw press, punchinglpress forming, sheet bending machine.

\section{Introduction}

Currently the machine building industry uses 4 types of presses for metal forming: crank, cam, screw and hydraulic. They have a long history and have been used for years. Each has advantages and disadvantages. A crank press is the most widely one used in mechanical engineering. It is simple in design, has speed of operation, but it also has some disadvantages [1].

A new type of a mechanical press has been developed in this study - a cam-screw type - propeller howl, which in his view has some serious advantages over the crank press and may easily replace it in production [2-3].

\section{Materials and Methods}

A cam-screw press consists of the following components (see Fig. 1): the drive shaft 1, the cylinder 2 , which is coaxially fixed on the drive shaft. The cylinder has a conical screw surface 3 with an angle of inclination of ruling AE relative to the drive shaft axis 1 equal to $\alpha$. The surface has a bevel with angle of inclination $\beta$ relative to the horizontal [4]. A slide 4 is fixed under the cylinder 2 . It can freely and vertically move around the axis in the housing 5 . The upper part of the slider 4 has a concave surface 6 that can contact with the screw surface 3 and has a tilt angle to the horizontal equal to $\beta$. Fig. 2 shows a general view of the press.

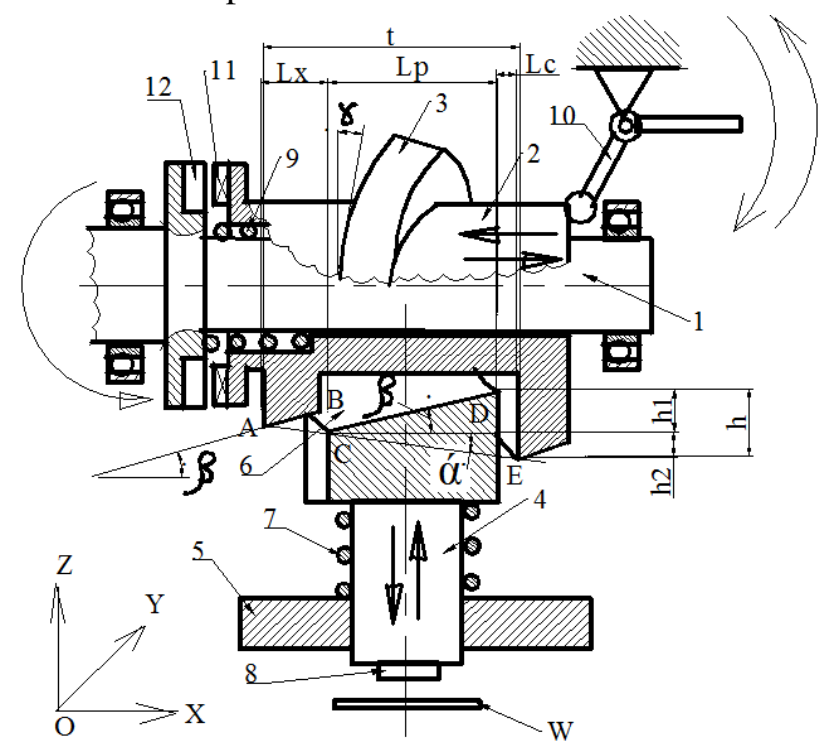

Fig. 1. Scheme of the press

The drive shaft 1 together with the cylinder 2 rotates by a drive. A low ruling $\mathrm{AB}$ of a screw surface 3 moves along the axis of the shaft 1 approaching the surface 6 . When $\mathrm{AB}$ moves at a distance Lx it comes into contact with the ruling CD of the surface 6. The screw or helical surface 3 and the surface 6 come into contact forming a contact area. Helical surface 3 presses on the surface 6 and slide 4, which moves downward and compresses the spring 7. The instrument 8 moves together with the slide 4 , the slide makes a push into the workpiece W. Slider 4 moves down until point A of the ruling 
$\mathrm{AB}$ coincides with point $\mathrm{D}$ of the ruling $\mathrm{CD}$. The low ruling $\mathrm{AB}$ at that time passes the working length $L_{P}$.
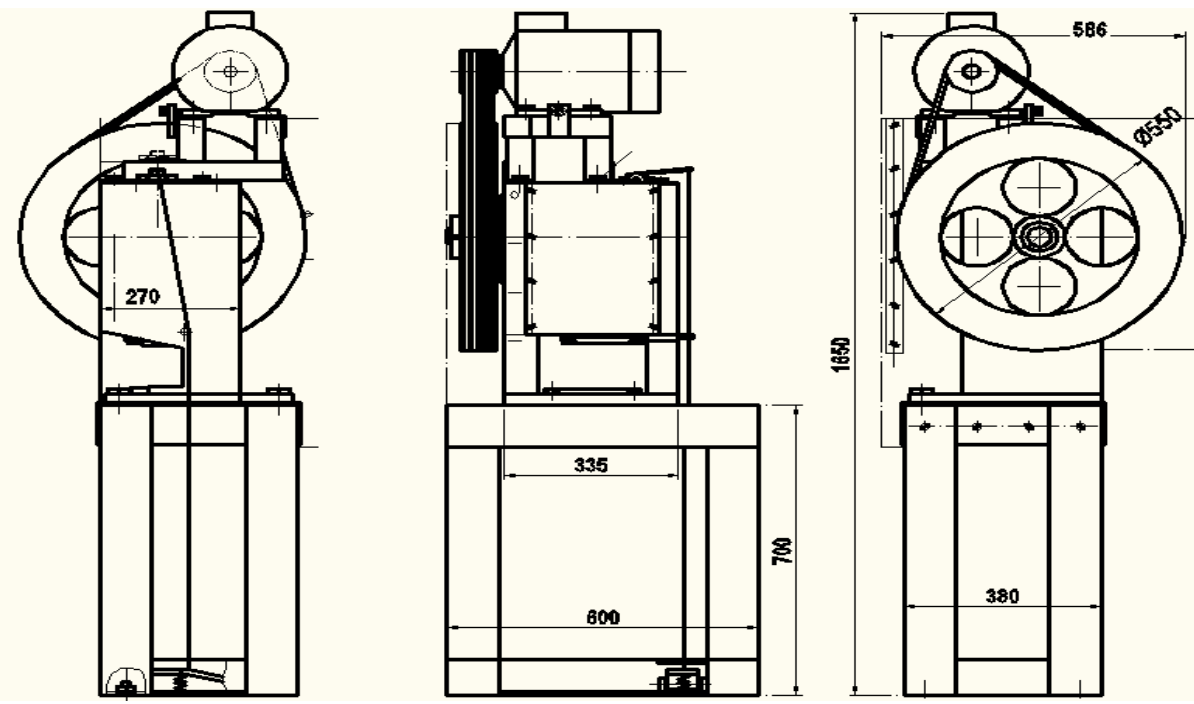

Fig. 2. Press general view

Thereafter, the contact of the surface 3 and 6 moves apparat making the slide 4 in tandem with the surface 6 and the instrument 8 by the action of the spring 7 rises up to take its initial position. After that point $\mathrm{A}$ is still going through the distance equal to Lc, after which the helical surface 3 completes one full turn and the whole cycle repeats again. These surfaces are constantly lubricated for them to move freely relative to each other and reduce frictional force [6-7].

To turn off the press for it not to work in idle conditions one should turn the cylinder 2 to the right by the switching mechanism 10 . The cylinder cams 11 are disengaged from slots 12 of the clutch and the cylinder 2 out of engagement with the grooves 12 of the coupling half and the cylinder 2 freely rotates regarding the shaft 1 . If to press the cylinder 2 by the screw 9 designed to bring it out of engagement with the shaft 1 , the surfaces 3 and 6 contact opening will be happening automatically after each cycle. Closing of jaws 11 slots 12 is produced by turning the mechanism 10 to the left.

As the proposed mechanism has the properties of the power one, it can be regarded as a three-lobe mechanism: one lobe is inclination at the angle $\gamma$, the second lobe is the helix angle $\alpha_{a}$ of Archimedes' spiral in the plane YOZ (see Fig 3), the third lobe - bevel of a helical surface itself at the angle. The values of the resulting power $P_{0}$ depending on the rotary force $Q$ are equal to:

$$
\begin{gathered}
P_{0}=\frac{Q \cdot \frac{h_{1}}{h}}{\operatorname{tg} \gamma \cdot \operatorname{tg}(\beta+\psi)}+\frac{Q \cdot \frac{h_{2}}{h}}{\operatorname{tg}\left(\alpha_{a}+\psi\right)} \\
\operatorname{tg} \alpha_{a} \approx \frac{\Delta R}{2 \pi \cdot \operatorname{Ricp}}=\frac{\operatorname{t} \cdot \operatorname{tg} \alpha}{2 \pi \cdot \operatorname{Ricp}}
\end{gathered}
$$

where $h_{1}=L_{P} \cdot \operatorname{tg} \beta$;

$h_{2}=L_{P} \cdot \operatorname{tg} \alpha$

$\psi$ - angle of friction;

$R_{i c p}$ - average radius of Archimedes' spiral;

$\Delta R$ - increase of Archimedes' spiral radius in one revolution (see Fig. 3).

Express the power $P_{0}$ through the torque $M$ :

$$
P_{0}=\frac{M \cdot \frac{h_{1}}{h}}{\left(R_{0}+\frac{t \cdot \operatorname{tg} \alpha \cdot \varphi_{i}}{360^{\circ}}\right) \operatorname{tg} \gamma \cdot \operatorname{tg}(\beta+\psi)}+\frac{M \cdot \frac{h_{2}}{h}}{\left(R_{0}+\frac{t \cdot \operatorname{tg} \alpha \cdot \varphi_{i}}{360^{\circ}}\right) \operatorname{tg}\left(\alpha_{a}+\psi\right)}
$$


where $R_{0}$ - initial vector-radius;

$\varphi_{i}$ - shaft degree.

For example, let us define $R_{0}$ with the following initial data: $M=100 \mathrm{Nm}, R_{0}=0.1 \mathrm{~m}, \alpha=15^{\circ}$, $\beta=15^{\circ}, \psi=5.5^{\circ}, \varphi_{i}=180^{\circ}, t=0.08 \mathrm{~m} t=0.08 \mathrm{~m}$. Power $P_{0}$ is equal to $13222 \mathrm{~N}$, the slider mechanism stroke is $42.9 \mathrm{~mm}$.

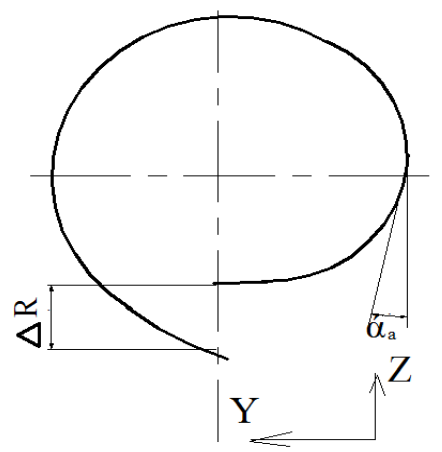

Fig. 3. Archimedes' spiral of a conic screw surface in the YOZ plane

\section{Experimental Setup}

The proposed press markedly outperforms the existing crank press.

1. This press, depending on the type of processing, consumes electric power $1.5-2$ times less than the crank press, because the push applied on the slide during the entire working cycle is transmitted uniformly and is not lossy [8]. As for a crank-slider, in a crank press it on the contrary practically does not transmit its efforts on the slider at the beginning and at the end of a stroke due to having small values of the power angle. The effective phase of power transmission in this mechanism makes up approximately $90^{\circ} \varphi$ of the crank angle. As an example, let us consider the following crank press parameters: throw of crank $-40 \mathrm{~mm}$, crank length $800 \mathrm{~mm}$, rolling force of the crank attached at its end and perpendicular - $50000 \mathrm{~N}$. Let us cite computed data for determination of the force $P_{0}$ acting on the workpiece. The table shows that $P_{0 \max }=49875 \mathrm{~N}$, the rotary angle is $90^{\circ}$. The effective phase of the crank rolling is $60-150^{\circ}$ (see Fig. 3).

Table 1

\section{Design parameters of the press machine}

\begin{tabular}{|c|c|c|c|c|c|c|c|c|c|}
\hline $\begin{array}{c}\text { Crank angle of } \\
\text { rotation, degree }\end{array}$ & 0 & 30 & 60 & 90 & 120 & 150 & 160 & 170 & 180 \\
\hline Power $P_{0}, \mathrm{~N}$ & 0 & 23902 & 42139 & 49875 & 44301 & 26067 & 17899 & 9109 & 0 \\
\hline
\end{tabular}

2. The press has a short idling time equal to $15-20 \%$, the crank press has a share of idle time equal to $50 \%$ (see Fig. 4), consequently, the performance of the new press will be higher [10].

3. The slide of the press moves uniformly during the working stroke and the slide of the crank press moves uniformly and with acceleration. The uniform movement of the slider reduces the wear rate of the tool by approximately $20 \%$.

4. The operating force of the new press slider during the entire stroke is kept uniform and at the end of the stroke it is likely to increase without hard braking of the flywheel. This greatly reduces the probability of the press entry into "stupor regime". Also, at the approach of the slider to the most downward position the spring force becomes maximized and the contact opening of the slider and the helical surface force of the spring allow the slide to recover place, overcoming the resistance of the machined workpiece. In contrast, the design of the crank press has a return force equal to zero in the lowermost position [9]. When the press approaches the lowermost position its pressing force tends to zero. The press just may come short of enough force to force in the last millimeter of the workpiece. If, however, the press was able to go to its lowest position, then in theory the crank press cannot take off the slider together with the tool after its forcing into the work piece. But in practice, due to elastic deformation of links, gaps, the force of inertia of the flywheel rotation, etc., there remains a little portion of force. It makes just a small percentage of the force 
attached to the shaft of the press. This force returns the slider to its original position, but as it was mentioned the value of the force is small, and the press can come into a stupor position. Also, at that time the efficiency of the press is extremely small - it is about 2-3\% (see Fig. 4).

5. Kinematic diagram of the press has no special brake assembly as the crank press; its functions are performed by surfaces 3 and 6 . The press mechanism provides automatic trip out of the slider in its topmost position in the press. This improves the press stopping reliability, reduces energy costs on mechanism braking and reduces wear.

6. Work of the press clutch carried out in relaxed conditions and when you turn it on, undergoes dynamic efforts twice as weakened. Reduction of dynamic forces is achieved by the fact that the new press does not need stop the press shaft, which has constant rotation due to the absence of the connecting rod in the press.

7. The press has no connecting rod that enables to reduce the overall height of the press by approximately $15-20 \%$.

8. Kinematic chain of the new press has only two links - a screw cylinder and a slider. The crank press has three links - a crank, a connecting rod and a slider. The new press is expected to have high stiffness, thus increasing its accuracy and durability.

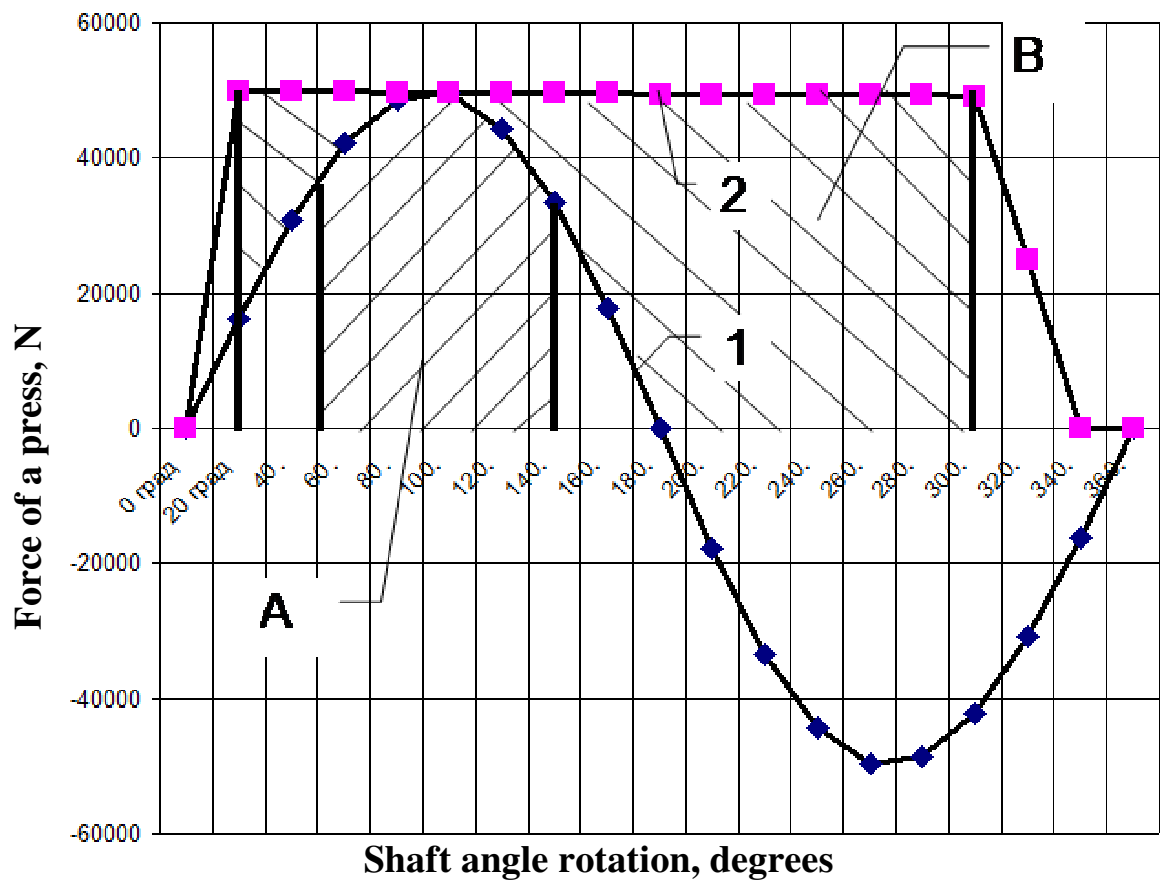

Fig. 4. Dependence of power of the press on the shaft angle of rotation: 1 - crank press; 2 -new press. Effective zone of work: A - crank press, B - new press

According to the proposed scheme, there was produced a working press. Fig. 5 shows a drawing of the press general view. Fig. 6 - a general view of photo of the press.

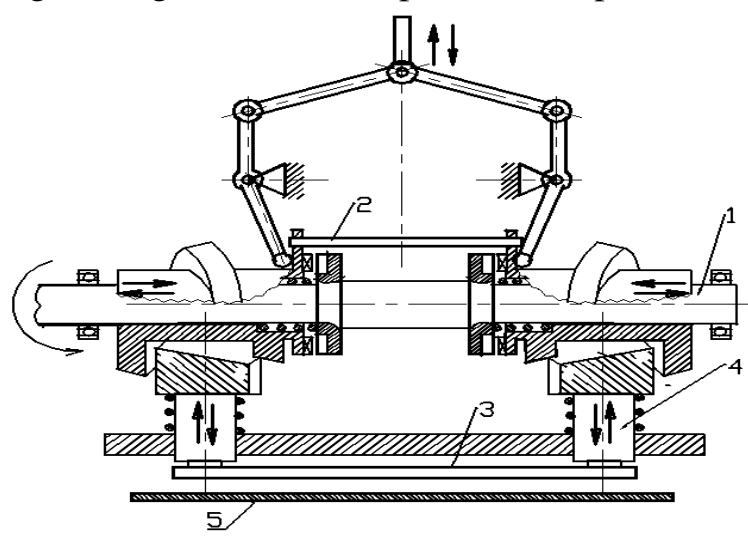

Fig. 5. Scheme of a sheet bending machine 

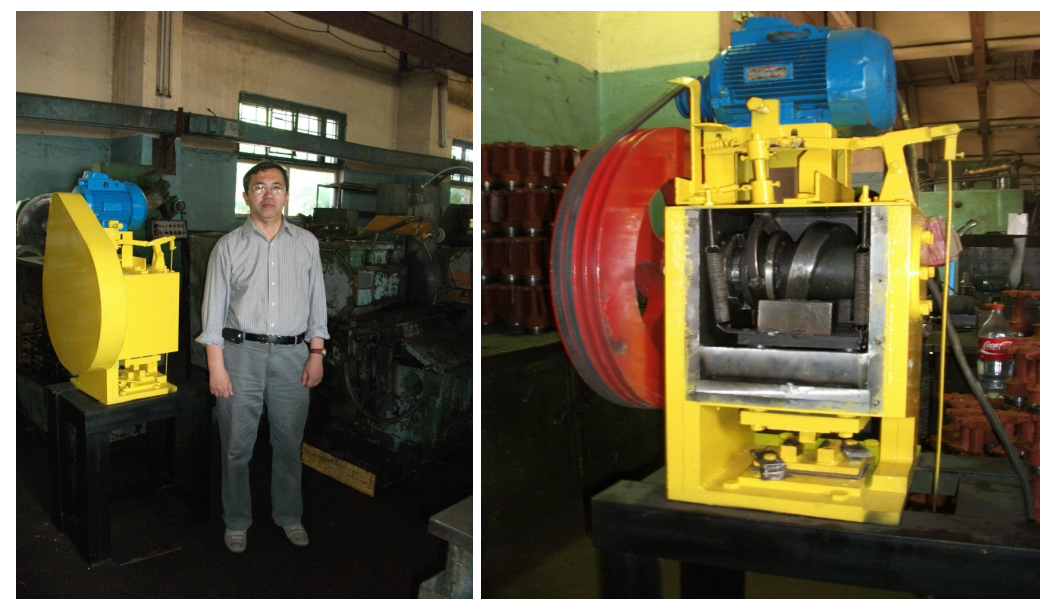

Fig. 6. Photo of a general view of the press

Press features: force $50-55 \mathrm{kN}$, drive power $1.5 \mathrm{~kW}$, slider stroke $35 \mathrm{~mm}$, shaft speed $120 \mathrm{~min}^{-1}$, rate of rotation $600 \times 586 \times 1650 \mathrm{~mm}$. Successful tests of the press - pressure forming of steel billets 2 mm thick, width $36 \mathrm{~mm}$, depth of drawing $32 \mathrm{~mm}$, stainless steel (see Fig. 7).

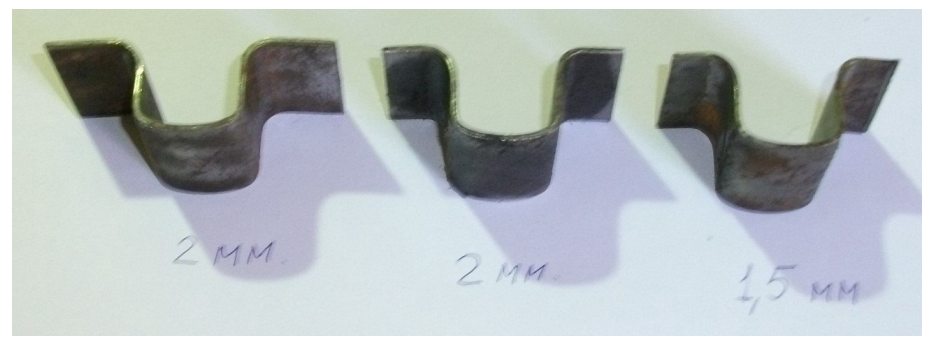

Fig. 7. Photo of stamped products

\section{Results and discussion}

The proposed scheme of the press can be used in the construction of a sheet bending machine. In this scheme, it is necessary to use two identical mechanisms working synchronously. As shown in Fig. 5 , the design of thick bending machine consists of two identical mechanisms fixed dosimetrically on the same shaft 1.To synchronize rotation of cylinders they are connected by the connecting rod 2, but can move axially regarding each other. A common tool 3 is placed on two slides 4 , which puts pressure on the work piece 5 .

Dissymmetrical arrangement of two mechanisms enables to destroy horizontal axial components of forces produced by slides 4 , which are multidirectional and have the same value.

\section{Conclusions}

1. A new type of mechanical press with at least 8 improvements compared with the basic type presses - the crank one.

2. A prototype of a new type press is manufactured and successfully tested.

3. A design of a new sheet pressing machine is offered with use of a new type press mechanism.

\section{References}

1. Svistunov V.E. Forging-pressing equipment. Crank presses, Moscow State Industrial University, 2008, pp. 680-690.

2. Askarov E.S. Mechanical press based on a cam-screw mechanism with variable structure. Materials of the International Conference Mechanisms of variable structure and vibration machines, Kyrgyzstan, 1995, pp. 93-96.

3. Patent 3380 Kazahstan, ICI F16H25 / 08, Cam-screw mechanism. E. S. Askarov (RK): appl.24.01.94: Publ. 06.10.96, Bull. pp. 2-4. 
4. Patent 2627 Kazahstan, ICI B30B01 / 26, Mechanical press of E. S. Askarov. Filed on 7/26/93: issues on 15.06.98, Bull. pp. 5-4.

5. Askarov E.S. Mechanical press based on a cam mechanism with enlarged contact spot. Russian engineering research, Vol. 23, 2003, pp. 1-8.

6. Mazzu Q. Study Design \& Prototyping of an animal traction cam based press for biomass densification. Mechanism and Machine Theory, Vol-42, 2007, pp. 652-667.

7. Doege E., Hindersmann M. Optimized Kinematics of Mechanical Presses with Noncircular Gears. Annals of the CIRP, Vol-46, No.1, 1997, pp. 213-216.

8. Dwivedi S.N. Application of Whitworth Quick Return Mechanism for high velocity impacting press. Mechanism and Machine Theory, Vol-19, No. 1, 1984, pp. 51-59.

9. Algazy Z., Gulnar M., Kuanysh A., Aizhan S., Raushan A. The kinematic analysis of flat lever mechanisms with application of vector calculation. Vibroengineering Procedia, Vol. 8, 2016, pp. 1-5.

10. Algazy Z., Kuanyshkali A., Aizhan S., Adilet Z., Raushan A., Zhastalap A. The synthesis of four-bar mechanism. Vibroengineering Procedia, Vol. 10, 2016, pp. 486-491. 